relapsed after an interval, but none to date have had a lesion in the same site, although they stated that this had always occurred previously. It remains to be seen to what extent the treatment is curative when it has been applied. Failure in method (inadequate cover of the whole affected area) may explain why some patients derived little benefit from the treatment, or the virus may have been I.D.U.-resistant. All strains isolated are being examined for this property. All lesions occurred on the face round the mouth, on the lips, and in one instance on the nose.

The unusual form of treatment presented no major practical problems in the group investigated. The patients feel a sharp impact, and may ooze a little blood from the entry wound for a minute or two. On the other hand many expressed delight with the (as it turned out) real shortening of the attack, and commented on the rapidity with which the unpleasant itching and tingling went, often within an hour. This seems to be a real advantage in the group treated with I.D.U. (10 of 12 in the active, 3 of 11 in the placebo group). We have since used the spray gun in the treatment of herpetic paronychia, and have found that the duration of the lesions was apparently shortened, that the virus disappeared or became very scanty after treatment, and that the patient experienced relief from the often excruciating pain in this condition.

\section{Summary}

Twenty-three patients with herpes of the face participated in a double-blind controlled trial to test the effect of 5-iodo-2'deoxyuridine (idoxuridine), $0.1 \%$ in aqueous solution. The solution was applied with a modified airgun for intradermal injection. In 12 patients receiving the active I.D.U. solution in a single treatment there was an average shortening of the duration of the lesion of 3.32 days (or $37 \%$ ) compared with the average duration (8.87 days) in 11 receiving saline. A true therapeutic effect of I.D.U. on herpes infections of the skin has been demonstrated.

Our thanks are due to Dr. T. A. Turnbull, of Smith Kline and French Laboratories Ltd., for the supply of I.D.U., and for a Dermojet "Mark 2 " airgun ; to Mr. B. A. Stone, of the workshop of the Regius Professor of Medicine's Department, for machining guards to our design; to Mr. Ivor Ohinn for his help with the virus cultures; and, not least, to our long-suffering patientsdoctors, medical students, nurses, and other members of the hospital staff-for their intelligent co-operation.

\section{REFERENCES} Burnett, J. W., and Katz, S. I. (1963). f. invest. Derm., 40, $7 . \dot{\text {. }}$
Juel-Jensen, B. E., and MacCallum, F. O. (1964). Brit. med. 987.

\title{
Outbreak of Dysentery Due to Contact with a Pet Monkey
}

\author{
D. T. ROBINSON,* M.SC., M.R.C.S., L.R.C.P., DIP.BACT., F.C.PATH. ; \\ ELIZABETH C. ARMSTRONG, $\dagger$ M.D., DIP.BACT., M.C.PATH. ; \\ K. PATRICIA CARPENTER, $\ddagger$ M.B., CH.B., DIP.BACT., M.C.PATH.
}

Brit. med. F., 1965, 1, 903-905

Apart from man, the simian primates are the only animals to suffer naturally from bacillary dysentery caused by organisms of the Shigella genus. Shigella infections in these animals have been well known to those in charge of monkey colonies since the early days of bacteriology (Grunbaum, 1904 ; Ravaut and Dopter, 1909), but with the importation of large numbers of primates for laboratory use in recent years the possible hazards of these and other natural infections of monkeys to human contacts have become more widespread. Though bacillary dysentery in humans is undoubtedly a much less serious disease than the rare but fatal infection caused by the monkey $B$ virus, Herpesvirus simiae, which may follow a monkey-bite or scratch, the incidence of shigella infections in imported monkeys is sufficiently high to constitute a potential risk. Ruch (1959) comprehensively reviewed both the published and unpublished records of the spread of bacillary dysentery from monkeys to human contacts, and, though the number of such incidents is small, fatalities have occurred (Bach et al., 1931).

Laboratory workers and curators of primate colonies are aware of these hazards, but outside such circles the risks of human association with monkeys are not widely known, and there is some evidence that increasing numbers of monkeys are being bought as household pets by the public. These pets, whether bought in this country from pet stores or brought in from abroad by returning travellers, are not subject to any quarantine regulations and probably only very few are inspected

\footnotetext{
* Director, Public Health Laboratory, Liverpool ; Associate Professor of Bacteriology, University of Liverpool.

t Senior Bacteriologist, Public Health Laboratory, Liverpool.

‡ Director, Dysentery Reference Laboratory, Colindale, London.
}

by a veterinary surgeon. Children, being particularly susceptible to shigella infections, are at special risk from monkey pets. Carpenter and Sandiford (1952) drew attention to this point, and in a memorandum prepared by the British Veterinary Association Exotic Animals Subcommittee Appleby et al. (1963) likewise recommended the collaboration of veterinary surgeons and medical practitioners in advising and educating the public about monkey pets. The outbreak described here well illustrates the unsuitability of a monkey as a domestic pet.

\section{Index Case}

The index case, D. H., was a girl aged 2 years who developed severe diarrhoea on 15 February 1963 and was admitted to hospital next day. The child apparently mentioned to the ward sister that her uncle had brought home a pet monkey. From the specimen of the child's faeces a strain of Shigella flexneri was isolated and the local medical officer of health was notified accordingly. The strain was subsequently identified as $S h$. flexneri $\mathrm{Y}$ and had the epidemiologically useful marker of being catalase-negative, a rare finding in Sh. flexneri (Carpenter and Lachowicz, 1959). The records at the Dysentery Reference Laboratory show that Sh. flexneri $\mathrm{Y}$ is more often encountered in primates than in human beings, so it was very suggestive that the monkey was implicated in the child's disease. The epidemiological investigation which followed reyealed an interesting story, told now for clarity in chronological order. Details of the families and cases involved are given in Table I. 
TABLE I.-Details of Cases

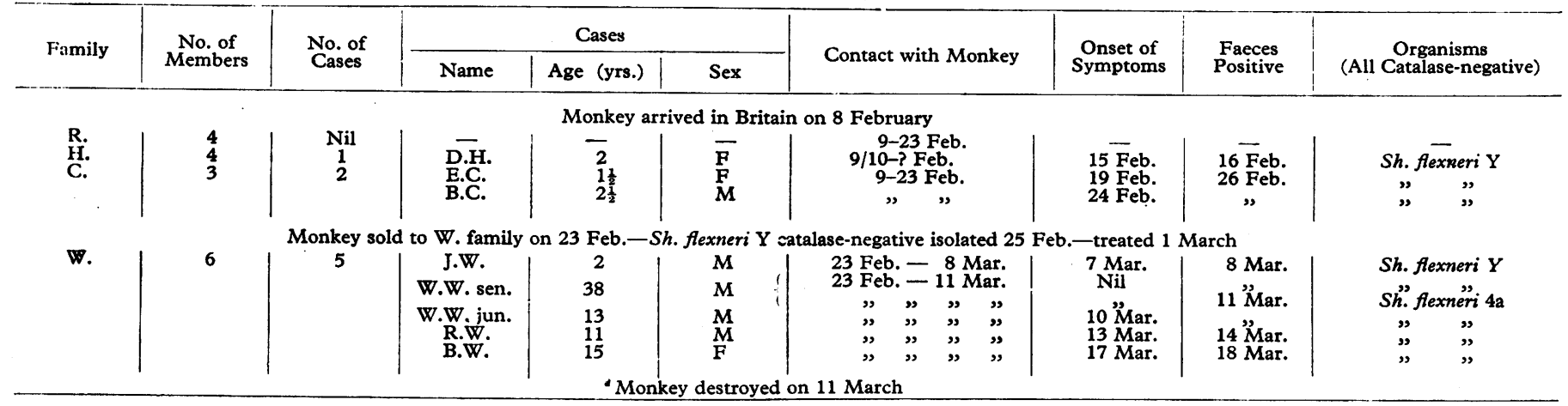

\section{Epidemiology}

The child's uncle, F. R. aged 18, was an assistant steward on a merchantman, and during an outward-bound voyage from South Wales to Brazil bought a pet monkey (probably the West African mona guenon, Cercopithecus mona) at St. Vincent, Cape Verde Islands, on 18 December 1962. There was no illness among the crew during the voyage to Brazil. On arrival in port on 31 December the monkey was examined by the Port Health Authorities and a sample of blood taken, which was reported as "negative." (This test may have been for the detection of yellow-fever antibodies.) The ship left port on 22 January 1963 and during the return journey to England several members of the crew, including F. R., had diarrhoea, but at no time did the monkey show signs of illness. F. R., as steward, served food to the crew. The ship arrived back in Wales on 8 February, when the crew were paid off, and F. R. reached home with his monkey the following day. Living in the same house as F. R.'s family was another family, the C.s.

\section{The Outbreak}

On either 9 or 10 February F. R. took his monkey with him on a visit to relatives, the $H$. family, at another address. The index case, the child D.H., belonged to this family, and she developed severe dysentery five or six days after her uncle's visit. The two children of the family C. then developed dysentery the following week and strains of catalase-negative Sh. flexneri $\mathrm{Y}$ were isolated from their faeces. Only these three children of the families $\mathrm{C}$. and $\mathrm{H}$. were ill, and even on repeated sampling no other member of their families nor any of the $R$. family was found to be excreting shigellae. At no time since his return home did the owner of the monkey have any diarrhoea nor were shigellae isolated from his faeces.

During these investigations, but before the monkey was proved to be a carrier, it was sold by its owner on 23 February to the father of the fourth family involved, the W.s. However, on 25 February a strain of catalase-negative Sh. flexneri Y was isolated from a sample of the monkey's faeces though the animal never showed any sign of illness. Treatment of the monkey was started on 1 March, but what was given is unknown. Four follow-up faecal specimens from the monkey were all negative, as were the first faecal specimens taken on 4 March from the two adults and four children of the W. family. Nevertheless, the youngest son of the W. family developed such severe dysentery on 7 March that he was admitted to hospital the following day and from his faeces catalase-negative Sh. flexneri $\mathrm{Y}$ was isolated. At the same time, faeces from the child's father, who was symptomless, yielded a similar organism.

In the next week all three older children of this family suffered attacks of dysentery and Sh. flexneri was isolated from them, and again from their father though he remained symptom-free. However, these four strains of shigellae, though catalase-negative, proved to be of the serotype $S h$. flexneri 4 a and not Sh. flexneri $\mathrm{Y}$.
An administrative decision was made on 11. March that the monkey should be destroyed, and this effectively ended the episode.

\section{Bacteriological Findings}

Serology.-The six strains of Sh. flexneri $Y$ and the four strains of Sh. flexneri 4a gave typical reactions in the appropriate absorbed diagnostic sera. Boyd (1938) described a variation in Sh. flexneri in which the major or type antigen is permanently lost, the organism retaining only its group antigen complex. Sh. flexneri $\mathrm{Y}$ is such a group phase variant, and, though it may be derived from a number of antecedent typespecific $S h$. flexneri serotypes, it most frequently arises from $S h$. flexneri 4a. After the isolation of the first strain of $S h$. flexneri $4 \mathrm{a}$, attempts were made by colony selection to find type-specific $S h$. flexneri 4a organisms in the $\mathrm{Y}$ cultures from the earlier cases and likewise Sh. flexneri Y organisms in the $4 \mathrm{a}$ cultures, but none was found. It was not, however, possible to go back to the orginal plates used for isolating the strains to examine all the colonies in detail, and it was unfortunate that a post-mortem examination was not done on the animal, as cultures taken then might have yielded both $S h$. flexneri $4 \mathrm{a}$ and $\mathrm{Y}$.

Biochemistry.-The 10 strains of shigellae isolated from the patients and the monkey were, regardless of antigenic structure, biochemically identical as shown in Table II. The reactions in the left and middle columns are characteristic of many serotypes of Sh. flexneri and Sh. boydii and therefore of no major value in confirming the identity of the strains, but since the indole reaction of strains of $S h$. flexneri 4 a and $S h$. flexneri $\mathrm{Y}$ may be either positive or negative the positive reaction given by all 10 strains is consistent with the strains being epidemiologically related, as is the similarity of fermentation reactions in the less routinely used carbohydrates, given in the right-hand column of Table II. However, the strongest evidence that the strains were epidemiologically related was the negative catalase reaction. Carpenter and Lachowicz (1959) suggested that, within the serotype $S h$. flexneri 4 a and the related $S h$. flexneri $\mathrm{Y}$, a negative catalase reaction might prove useful as a marker of strains for epidemiological purposes.

Drug-sensitivity Pattern.-Using Oxoid Multodisks on lysedblood agar plates, the 10 strains showed an identical pattern.

\begin{tabular}{|c|c|c|c|c|}
\hline $\begin{array}{l}\text { Glucose } \\
\text { Lactose } \\
\text { Mannitol } \\
\text { Sucrose } \\
\text { Dulcitol } \\
\text { Salicin } \\
\text { Xylose } \\
\text { Adonitol } \\
\text { Inositol } \\
\text { Urease } \\
\text { H2S } \\
\text { Motility } \\
\text { Indole }\end{array}$ & $\begin{array}{l}\frac{\mathbf{A}}{\mathbf{A}} \\
\overline{-} \\
\overline{-} \\
\overline{-} \\
\overline{-} \\
\overline{+}\end{array}$ & $\begin{array}{l}\text { Phenylpyruvic acid } \\
\text { M.R. } \\
\text { V.P. } \\
\text { Growth in citrate } \\
\text { Growth in KCN } \\
\text { Malonate } \\
\text { Gluconate } \\
\text { Gelatin liquefaction } \\
\text { Oxidase } \\
\text { Nitrate reduction } \\
\text { Decarboxylases: } \\
\text { Arginine } \\
\text { Lysine } \\
\text { Ornithine }\end{array}$ & $\begin{array}{l}\overline{+} \\
\bar{z} \\
\bar{z} \\
\bar{z} \\
\overline{+} \\
\overline{-}\end{array}$ & $\begin{array}{l}\text { Arabinose } \\
\text { Cellobiose } \\
\text { Dextrin } \\
\text { Glycerol } \\
\text { Maltose } \\
\text { Raffinose } \\
\text { Rhamnose } \\
\text { Sorbitol } \\
\text { Trehalose } \\
\text { Catalase }\end{array}$ \\
\hline
\end{tabular}

*A = Acid production within 48 hours. (a) = Weak and delayed acid production. 
They were resistant to sulphonamide but sensitive to chloramphenicol, streptomycin, tetracycline, and furazolidone.

\section{Discussion}

It is generally accepted that the risk to adult handlers of acquiring shigella infection from primates in zoos and laboratories is not great (Ruch, 1959 ; Appleby et al., 1963). However, when the contact is the intimate household fondling of a newly obtained and exotic pet, there is a very real risk of the spread of shigellae to the family from an apparently healthy animal with an unsuspected infection, and the children are especially vulnerable, as shown clearly in this outbreak.

Apart from the index case, who probably had contact with the monkey during a single visit, the other families were in close domestic contact with the animal for two to three weeks. Though the precise incubation period of the disease cannot be determined in this instance, the dates of onset of symptoms in the patients were compatible with the presence of the monkey in the household. Of the 17 persons at risk, seven children developed dysentery, but the single adult infected was symptomless. Two children had severe attacks, but fortunately there were no deaths, unlike the tragedy in Germany reported by Bach et al. (1931) in which three children, under 5 years old, died out of 17 human cases following household contact with five guenons brought from West Africa as pets. In that incident the infecting organism was also Sh. flexneri $Y$.

The significance, if any, of the monkey's presence on board to the outbreak of diarrhoea among the ship's crew cannot be assessed, as it is not known when the animal itself was infected.

\section{Conclusions}

As the public are probably quite unaware of the danger of monkey pets, both medical practitioners and veterinary surgeons in general practice who are not normally concerned with simian problems should be alert to the potential hazards of the presence of a pet monkey in a household and should discourage families, particularly those with young children, from acquiring monkeys as pets. Whenever an infectious illness occurs within a household having a pet monkey, whether the index case is human or animal, the family should be urged to have the other human and simian members examined by the appropriate practitioner and the necessity explained to them of adopting measures to prevent the spread of disease between human and simian contacts.

\section{Summary}

An outbreak of bacillary dysentery is described, involving seven children and one adult out of 17 persons at risk, following household contact with a newly imported pet monkey. $S h$. flexneri $\mathrm{Y}$ was isolated from four children and the monkey. From the other three children $S h$. flexneri 4a was isolated, and the adult, who remained symptomless, was found to be excreting Sh. flexneri $\mathrm{Y}$ and Sh. flexneri $4 \mathrm{a}$ on separate occasions.

All the strains of Sh. flexneri, irrespective of serotype, had the rare and epidemiologically useful marker of being catalase-? negative. This fact and the known antigenic relation of $S h$. flexneri $\mathrm{Y}$ to Sh. flexneri $4 \mathrm{a}$ combined with the sequence of the infections following the sojourn of the monkey within the different families are very suggestive that the cases constituted a single outbreak.

The attention of medical practitioners and veterinary surgeons in general practice is drawn to the risks of shigella infections spreading from pet monkeys to their human contacts, and it is urged that the public should be warned of the unsuitability of monkeys as domestic pets, particularly where there are young children in a household.

Our thanks are due to Dr. T. R. Roberton, Medical Officer of Health for Bootle, for his help in obtaining the epidemiological data.

\section{REFERENCES}

Appleby, E. C., Graham-Jones, O., and Keeble, S. A. (1963). Vet. Rec., Bach, F. W. W., Fülscher, J., and Harnack (1931). Veröff. Med.-Vereo., 34, 61. Quoted from Ruch (1959).

Boyd, J. S. K. (1938). F. Hyg. (Camb.), 38, 477 Carpenter, K. P., and Lachowicz, K. (1959). F. Path. Bact., 77, 645. and Sandiford, B. R. (1952). Brit. med. f., 1, 142. Grunbaum, A. S. (1904). Ibid., i, 817.

Ravaut and Dopter (1909). Bull. Śoc. Path. exot., 2, 17

Ruch, T. C. (1959). Diseases of Laboratory Primates, Chap. 3. Saunders, London.

\section{Materials and Methods}

Sulphorthodimethoxine is 4-sulphanilamido-5,6-dimethoxypyrimidine, a long-acting sulphonamide known formerly

by the experimental number Ro 4-4393, and now by the proprietary name of Fanasil; it is an isomer of sulphadimethoxine (Madribon) but with a biological half-life of 100 to 200 hours, so that a weekly dosage is sufficient for therapeutic purposes. It was supplied by Roche Products Ltd. in the form of $500-\mathrm{mg}$. tablets and a liquid suspension containing $100 \mathrm{mg} . / \mathrm{ml}$.

The patients were semi-immune Bantu Africans who were suffering from acute attacks of malaria. Fifteen were treated as in-patients at St. Augustine's Mission Hospital, Magila, 10 miles $(16 \mathrm{~km}$.) east of Amani in the Usambara foothills, and nine as out-patients at the Amani Institute; one patient was treated at Muheza Government Hospital, two miles (three $\mathbf{k m}$.) from Magila. So far as could be determined no patients selected had received antimalarial drugs prior to treatment with sulphorthodimethoxine.

Thick and thin blood films were taken daily, but this was possible for only as long as a patient would stay in hospital or return for examination as an out-patient. Parasites were 